\title{
Simultaneous Detection of Six Different Types of Pesticides by an Immunosensor Based on Surface Plasmon Resonance
}

\author{
Shiro MiYaKe, $* 1, * 2, * 3 \dagger$ Yuki Hirakawa, ${ }^{* 1, * 4}$ Tomomi Yamasaki, $* 1, * 4, * 5$ Eiki Watanabe, $* 6$ \\ Ayako HARAda, ${ }^{* 7}$ Seiji IwaSa, ${ }^{* 7}$ and Hiroshi NARITA*4 \\ *1 Advanced Science, Technology \& Management Research Institute of Kyoto, Shimogyo, Kyoto 600-8813, Japan \\ *2 Advanced R\&D Center, HORIBA, Ltd., Minami, Kyoto 601-8510, Japan \\ *3 Azabu University, Sagamihara, Kanagawa 252-5201, Japan \\ *4 Kyoto Women's University, Higashiyama, Kyoto 605-8501, Japan \\ *5 Osaka Institute of Public Health, Higashinari, Osaka 537-0025, Japan \\ *6 Institute for Agro-Environmental Sciences, National Agriculture and Food Research Organization, Tsukuba, \\ Ibaraki 305-8604, Japan \\ *7 Toyohashi University of Technology, Toyohashi, Aichi 441-8580, Japan
}

\begin{abstract}
Six pesticides, azoxystrobin, boscalid, chlorfenapyr, imazalil, isoxathion, and nitenpyram, were simultaneously detected by using a surface plasmon resonance (SPR) immunosensor. The working ranges were $3.5-19 \mathrm{ng} / \mathrm{mL}$ for azoxystrobin, $4.5-50 \mathrm{ng} / \mathrm{mL}$ for boscalid, $2.5-25 \mathrm{ng} / \mathrm{mL}$ for chlorfenapyr, $5.5-50 \mathrm{ng} / \mathrm{mL}$ for imazalil, $3.5-50 \mathrm{ng} / \mathrm{mL}$ for isoxathion, and $8.5-110 \mathrm{ng} / \mathrm{mL}$ for nitenpyram. They showed adequate recovery results in tomato samples: $104-116 \%$ for azoxystrobin, $94-101 \%$ for boscalid, $90-112 \%$ for chlorfenapyr, $96-106 \%$ for imazalil, $107-119 \%$ for isoxathion, and $104-109 \%$ for nitenpyram. The correlation coefficient with liquid chromatography (HPLC or LC-MS/MS) using vegetable samples also agreed well: $0.91-0.99$ as $R^{2}$ without strong bias, except for nitenpyram for which the SPR immunosensor sensitivity was too low. The SPR immunosensor will have high applicability for pesticide residue analyses in vegetable samples.
\end{abstract}

Keywords Immunosensor, surface plasmon resonance, pesticide, insecticide, fungicide, monoclonal antibody

(Received September 7, 2019; Accepted October 11, 2019; Advance Publication Released Online by J-STAGE October 18, 2019)

\section{Introduction}

Pesticides are important chemical agents for crop cultivation. They include insecticides, fungicides, and herbicides. Insecticides are used to control insect pests and fungicides are used for crop diseases. Various insecticides having different action mechanisms have been developed and contribute to reduce the appearance of unwanted insect pests. Various types of fungicides have been also used to reduce unwanted microorganisms. More than several types of insecticides and fungicides are usually applied to crops during each of their cultivation periods in rotation to protect crops. ${ }^{1,2}$ Insecticides and fungicides are often applied immediately before the harvest to remove the insect pests and the lesioned parts from the harvested crops. They are therefore more likely to remain on the crops compared to the other pesticides, such as herbicides which are applied for weed control in the early stage of cultivation. $^{3-5}$ Further, residues of postharvest fungicides such as azoxystrobin and imazalil would remain in most cases when the crops are consumed..$^{3-5}$

S. M. and Y. H. contributed equally to this work.

$\uparrow$ To whom correspondence should be addressed.

E-mail: s-miyake@azabu-u.ac.jp
Pesticide residue analyses are important to ensure food safety. The maximum residue limits (MRLs) of all pesticides have been defined for combinations with all crops based on the Food Sanitation Act in Japan since 2006. The pesticide residues are generally detected by gas or liquid chromatography (GC or LC) with mass spectrometry (MS). ${ }^{6-9} \quad$ Such chromatography techniques sensitively and accurately detect more than 50 - 200 kinds of pesticides simultaneously, but they require a lot of time to prepare measurement samples and also skilled techniques for the operations. As an alternative method, enzyme-linked immunosorbent assays (ELISAs) have been developed for the detection of pesticide residues in crops. ${ }^{10-13}$ Because the ELISAs are much simpler, faster, and more cost-effective than the GC or LC techniques, they have been used for the determination of pesticide residues in crop samples in farmers fields before shipping. ${ }^{14-18}$ The ELISAs however cannot detect multiple pesticides simultaneously. To overcome this weak point, an immunosensor based on surface plasmon resonance (SPR immunosensor) with microchannel type sensor chip was recently developed to detect fungicide boscalid and insecticide clothianidin and/or nitenpyram as illustrated in Fig. 1A. ${ }^{19}$ This SPR immunosensor was useful for detecting these pesticides, but it could not detect more than three pesticides, even though such numbers of pesticides are usually applied to crops. 

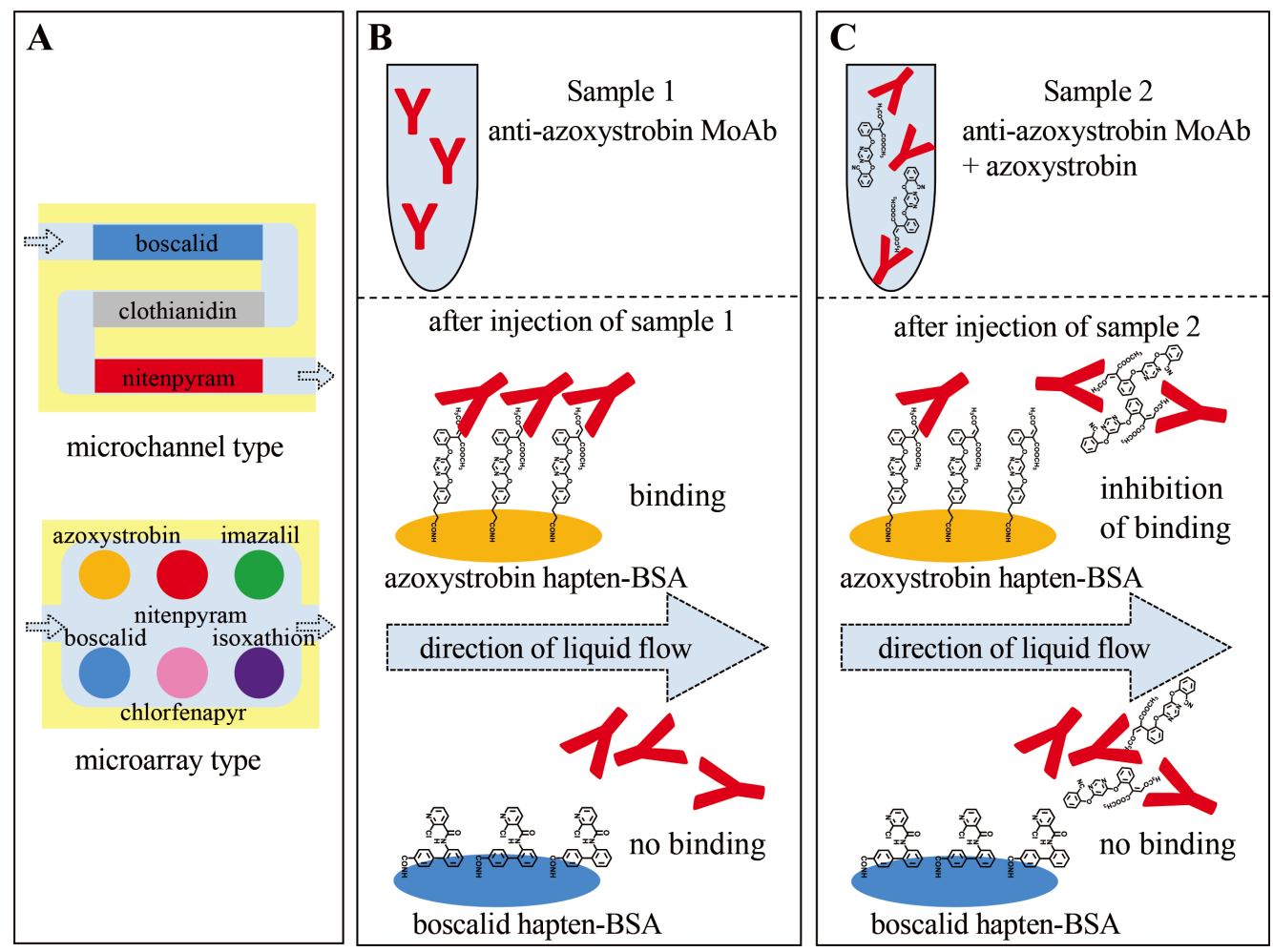

Fig. 1 Schematic illustration of pesticide determinations on sensor channels in SPR immunosensor: (A) Immobilized position of pesticide hapten-BSA conjugates and direction of liquid flow on microchannel type and microarray type of the sensor chips, (B) binding of anti-azoxystrobin MoAb with azoxystrobin hapten-BSA conjugate, and (C) inhibition of the binding by azoxystrobin.

In this study, it was described that six kinds of pesticide residues in vegetables and lemon were detected by using an SPR immunosensor with microarray type sensor chip as illustrated in Fig. 1A.

\section{Experimental}

\section{Chemicals and reagents}

Azoxystrobin, boscalid, imazalil, chlorfenapyr, isoxathion, and nitenpyram, as shown in Fig. 2 and which were of analytical grade for pesticide residue analysis, were purchased from Fujifilm Wako Pure Chemical Co. (Osaka, Japan). These pesticides were dissolved with methanol $(1.0 \mathrm{mg} / \mathrm{mL})$ and kept at $4{ }^{\circ} \mathrm{C}$ until use for SPR immunosensor or with acetonitrile $(1.0 \mathrm{mg} / \mathrm{mL})$ for high performance LC (HPLC) and LC with tandem MS detectors (LC-MS/MS). These pesticides were modified with carboxylic acid as shown in Fig. 2, called haptens in this study, and synthesized as described previously. ${ }^{10,12,19-22}$ All of the chemicals were collected for safe disposal discard after use. Anti-azoxystrobin monoclonal antibody (MoAb), anti-chlorfenapyr MoAb, anti-imazalil MoAb, anti-isoxathion MoAb, and anti-nitenpyram MoAb were provided from Horiba Ltd. (Kyoto, Japan). Anti-boscalid MoAb, which had been prepared in the previous study, was used. ${ }^{12}$ Bovine serum albumin (BSA: Prod. No. A7888) was purchased from SigmaAldrich Co. (St. Louis, MO). Each of the haptens was conjugated to BSA as described previously. ${ }^{12}$

All other chemicals and reagents used were of analytical grade, and purchased from Fujifilm Wako Pure Chemical Co. or Nacalai Tesque, Inc. (Kyoto, Japan).

\section{Constitution of SPR immunosensor}

An SPR imaging system (OpenPlex, Horiba Scientific, Palaiseau, France) was used for SPR immunosensor constitution. The sensor chip used was a glass prism of which the surface was coated with gold thin layer modified with alkane thiol having the carboxy group esterified by $N$-hydroxysuccinimide (SPRi-Biochip CS-HD, Horiba Scientific).

Each conjugate of haptens and BSA was prepared to $1 \mathrm{mg} / \mathrm{mL}$ with phosphate buffered saline (PBS: $10 \mathrm{mmol} / \mathrm{L}$ phosphate, $150 \mathrm{mmol} / \mathrm{L} \mathrm{NaCl} ; \mathrm{pH} \mathrm{7.0)}$ and was spotted at $10 \mathrm{~nL} / \mathrm{spot}$ onto the sensor chip. It was immediately let to stand at $4^{\circ} \mathrm{C}$ in wet atmosphere overnight. The chip surface was then washed with PBS. Unreacted carboxy groups were deactivated with $1 \mathrm{~mol} / \mathrm{L}$ ethanolamine solution (adjusted to $\mathrm{pH} 8.5$ ) at $25^{\circ} \mathrm{C}$ for $15 \mathrm{~min}$, and then washed with PBS. It was blocked with PBS containing $1 \% \mathrm{BSA}$ at $25^{\circ} \mathrm{C}$ for $15 \mathrm{~min}$ and was washed with PBS. The hapten-BSA conjugates immobilized sensor chip was set into the instrument. The set sensor chip was rinsed with the running buffer $(50 \mathrm{mmol} / \mathrm{L}$ phosphate buffer, $75 \mathrm{mmol} / \mathrm{L} \mathrm{NaCl}, 0.1 \%$ BSA, $0.02 \%$ tween 20 and $5 \%$ methanol; pH 7.0) at $50 \mu \mathrm{L} / \mathrm{min}$ until the SPR signal was stabilized.

\section{Analysis of pesticides by SPR immunosensor}

Each of the pesticide standard solutions was prepared to $0.4-400 \mathrm{ng} / \mathrm{mL}$ with $10 \%$ methanol. A mixture of the six kinds of pesticide standard solutions was also prepared to 0.4 $400 \mathrm{ng} / \mathrm{mL}$. On the other hand, each of the MoAb solutions was prepared to $5 \mu \mathrm{g} / \mathrm{mL}$ with high ion strength phosphate buffered saline (modified PBS: $100 \mathrm{mmol} / \mathrm{L}$ phosphate, $150 \mathrm{mmol} / \mathrm{L}$ $\mathrm{NaCl}$; pH 7.0) containing $0.2 \%$ BSA. A mixture of the six kinds of MoAb solutions was also prepared to each $5 \mu \mathrm{g} / \mathrm{mL}$. The pesticide standards, vegetable samples, or lemon sample 
<smiles>CO/C=C(/C(=O)OC)c1ccccc1Oc1cc(Oc2ccccc2C)ncn1</smiles>

azoxystrobin<smiles>CO/C=C(/C(C)=O)c1ccccc1Oc1cc(Oc2ccc(CCC(=O)O)cc2C)ncn1</smiles>

azoxystrobin hapten<smiles>C=CCOC(Cn1ccnc1)c1ccc(Cl)cc1Cl</smiles>

imazalil

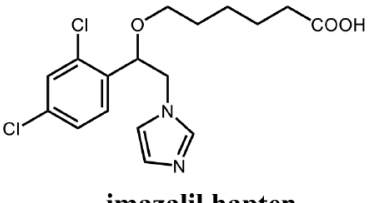

imazalil hapten<smiles>O=C(Nc1ccccc1-c1ccc(Cl)cc1)c1cccnc1Cl</smiles>

boscalid<smiles>O=C(O)c1ccc(-c2ccccc2NC(=O)c2cccnc2Cl)cc1</smiles>

boscalid hapten<smiles>CCOP(=O)(OCC)Oc1cc(-c2ccccc2)on1</smiles>

isoxathion<smiles>CCOP(=S)(CCCC(=O)O)Oc1cc(-c2ccccc2)on1</smiles>

isoxathion hapten<smiles>CCOCn1c(-c2ccc(Cl)cc2)c(C)c(Br)c1C(F)(F)F</smiles>

chlorfenapyr<smiles>N#Cc1c(Br)c(C(F)(F)F)c(CCCCCC(=O)O)n1-c1ccc(Cl)cc1</smiles>

chlorfenapyr hapten<smiles>CCN(Cc1ccc(Cl)nc1)/C(=C/[N+](=O)[O-])NC</smiles>

nitenpyram<smiles>CCN(Cc1ccc(Cl)nc1)/C(=C/[N+](=O)[O-])NCCCC(=O)O</smiles>

nitenpyram hapten

Fig. 2 Structure of azoxystrobin, boscalid, chlorfenapyr, imazalil, isoxathion, nitenpyram, and their haptens.

solutions described below were mixed with an equal volume of the MoAb solution. The mixtures were used as the measurement samples as illustrated in Figs. 1B and 1C.

The measurement sample was injected into the SPR immunosensor at $50 \mu \mathrm{L} / \mathrm{min}$ for $240 \mathrm{~s}$, and continuously changed to the running buffer. The SPR immunosensor was regenerated by removal of the bound MoAbs with sequential rinsing with $50 \mu \mathrm{L}$ of $50 \%$ acetonitrile, $50 \mu \mathrm{L}$ of $3.0 \mathrm{~mol} / \mathrm{L}$ guanidine hydrochloride in $1.0 \mathrm{~mol} / \mathrm{L}$ acetic acid $(\mathrm{pH} 1.9)$, $50 \mu \mathrm{L}$ of water, $50 \mu \mathrm{L}$ of $1 \%$ SDS and $50 \mu \mathrm{L}$ of $50 \%$ acetonitrile at $50 \mu \mathrm{L} / \mathrm{min}$.

\section{Preparations of crop samples}

Tomatoes were purchased from a market in Osaka city for the recovery examinations. They were homogenized in a blender (7011HB, Waring, CT). A mixture of six kinds of pesticides standard solutions was added to the homogenized sample $(5.0 \mathrm{~g})$ at each final concentration $(0.5,1$, and $3 \mathrm{mg} / \mathrm{kg})$ in a $50-\mathrm{mL}$ screw-cap tube.

Eggplants, green peppers, and tomatoes were cultivated in an experimental farm at the National Agriculture and Food Research Organization for correlation examination of azoxystrobin, boscalid, and nitenpyram. They were harvested 1 day, 3 days, 7 days, and 10 days after applying a mixture of 1000 -fold dilution of Bestguard containing $10 \%$ nitenpyram, 2000-fold dilution of Amistar 20 flowable containing 20\% azoxystrobin, and 1000-fold dilution of Cantus containing 50\% boscalid. The harvested vegetable samples were homogenized. The formulation containing chlorfenapyr and isoxathion were not commercially available. Their standard solutions were therefore spiked to the homogenized vegetable samples.
The spiked concentrations were $0.5,1,2$, and $5 \mathrm{mg} / \mathrm{mL}$. Lemons with imazalil were purchased from markets in Tsukuba city, Osaka city and Kyoto city, and were homogenized. All of their homogenized samples were kept at $-30^{\circ} \mathrm{C}$ until use.

For the SPR immunosensor, 5 grams each of vegetables and lemon samples were vigorously shaken with $25 \mathrm{~mL}$ of methanol by a reciprocal shaker (Shaker SA320; Yamato Scientific Co., Ltd., Tokyo, Japan) for $30 \mathrm{~min}$ to extract the pesticides into the liquid phase. The extract was centrifuged at $3000 \mathrm{rpm}$ for $10 \mathrm{~min}$ at room temperature. The supernatant was diluted to 8.5 -fold with distilled water to prepare $10 \%$ methanol equivalent solutions. It was further diluted with $10 \%$ methanol to adjust the concentrations to the working range of the SPR immunosensor.

For HPLC or LC-MS/MS, vegetables and lemon samples were prepared to detect azoxystrobin, boscalid, chlorfenapyr, imazalil, and isoxathion as described previously. ${ }^{17}$ They were prepared in parallel to detect nitenpyram as described previously. ${ }^{18}$ The details are described in Supporting Information: "Sample Preparation for HPLC or LC-MS/MS Analysis".

Azoxystrobin, boscalid, chlorfenapyr, and isoxathion were simultaneously analyzed by HPLC. Nitenpyram was analyzed by another condition in HPLC. Imazalil was analyzed by LCMS/MS. The details are described in Supporting Information: "HPLC Analysis" and "LC-MS/MS Analysis".

\section{Results and Discussion}

Pesticide used in this study

Immunoassays for pesticide analysis often react not only with 

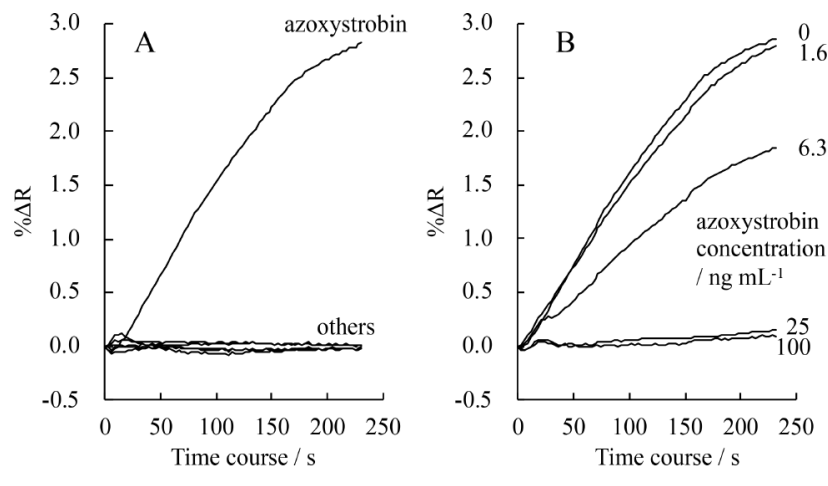

Fig. 3 (A) Time course of binding signal of anti-azoxystrobin MoAb with immobilized six kinds of pesticide hapten-BSAs. (B) Inhibition of the binding signal of anti-azoxystrobin MoAb with immobilized azoxystrobin hapten-BSA by azoxystrobin.

the target pesticide but also with the structurally related pesticides. ${ }^{19}$ These cross-reactions would be mainly derived from the similarity among the examined pesticide structures. When simultaneous detection of several pesticides is examined, the cross-reactivities would bring difficulty to the data analysis. Six pesticides were therefore chosen based on the difference of their structures. As shown in Fig. 2, azoxystrobin belongs to the strobilurin fungicide group, and the structure contains 3-methoxyacrylate. ${ }^{23}$ Boscalid belongs to the fungicide group containing pyridinecarboxyamide. ${ }^{24}$ Chlorfenapyr belongs to the insecticide group containing arylpyrrole. ${ }^{25}$ Imazalil belongs to the fungicide group containing imidazole. ${ }^{26}$ Isoxathion is a pesticide in the organophosphorus insecticide group that has phosphorothioate. ${ }^{27}$ Nitenpyram is a pesticide in the neonicotinoid insecticide group that has a nicotine-like structure. ${ }^{28,29}$

The haptens were synthesized based on the fact that the characteristic structures are kept, except for isoxathion in which the phosphate ester is unstable. It was expected that the hapten design would contribute to the specificity in the SPR immunosensor examined.

Reactivity between anti-azoxystrobin MoAb and six hapten-BSA conjugates, and its competitive inhibition by azoxystrobin

First, anti-azoxystrobin MoAb was injected into the instrument as illustrated in Fig. 1B. As shown in Fig. 3A, the signal from the spot of immobilized azoxystrobin hapten-BSA increased its time course dependently, but not the signals from spots of the other five hapten-BSAs. Thus, the anti-azoxystrobin MoAb specifically reacted with only azoxystrobin hapten-BSA. Next, the MoAb was mixed with various concentrations of azoxystrobin, and was injected sequentially as illustrated in Fig. 1C. As shown in Fig. 3B, the time course signal from the spot of immobilized azoxystrobin hapten-BSA was competitively inhibited by the azoxystrobin concentration dependently. The results showed that azoxystrobin could be quantitatively detected by the SPR immunosensor constituted without any cross reactions with the other haptens-BSAs.

The other MoAbs: anti-boscalid MoAb, anti-chlorfenapyr MoAb, anti-imazalil MoAb, anti-isoxathion MoAb, and antinitenpyram MoAb were also independently injected. As well as azoxystrobin, each MoAb was also specifically reacted with the corresponding pesticide hapten-BSA (data not shown), and the signals were competitively inhibited by the corresponding pesticide (data not shown). All of the MoAbs used in this study specifically reacted with their counterpart.
It is quite difficult that such MoAbs are prepared without careful hapten design and screening of hybridoma producing the MoAb against each of pesticides. The successful specificity is the result of repertory constitution of pesticide haptens and the corresponding MoAbs.

\section{Comparison of inhibition curves between each single MoAb and mixed six MoAbs}

Inhibition curve of azoxystrobin was drawn in Fig. 4A using the signal data on $230 \mathrm{~s}$ of Fig. 3B. And then, the six MoAbs mixture was mixed with various concentrations of six pesticides mixture and was injected sequentially. This inhibition curve for azoxystrobin was also drawn in Fig. 4A. The inhibition curve of the mixture with the six MoAbs and six pesticides was almost identical to that of the single MoAb for azoxystrobin. The 20\%, $50 \%$, and $80 \%$ inhibition concentration $\left(\mathrm{IC}_{20}, \mathrm{IC}_{50}\right.$, and $\left.\mathrm{IC}_{80}\right)$ values were $3.5,9.5$, and $19 \mathrm{ng} / \mathrm{mL}$ for the mixed MoAbs.

Inhibition curves of the other pesticides were also compared. As shown in Fig. 4B for boscalid, Fig. 4C for chlorfenapyr, Fig. 4D for imazalil, Fig. 4E for isoxathion, and Fig. 4F for nitenpyram, all of the inhibition curves were in good agreement between the mixed MoAbs and the corresponding single MoAb, although weak separations were found at low concentration range in nitenpyram. The separations can be however ignored because the working range was defined as the concentration between the $\mathrm{IC}_{20}$ value and $\mathrm{IC}_{80}$ value. The working ranges with the mixed MoAbs were $3.5-19 \mathrm{ng} / \mathrm{mL}$ for azoxystrobin, $4.5-50 \mathrm{ng} / \mathrm{mL}$ for boscalid, $2.5-25 \mathrm{ng} / \mathrm{mL}$ for chlorfenapyr, $5.5-50 \mathrm{ng} / \mathrm{mL}$ for imazalil, $3.5-50 \mathrm{ng} / \mathrm{mL}$ for isoxathion, and $8.5-110 \mathrm{ng} / \mathrm{mL}$ for nitenpyram. The SPR immunosensor constituted could be used for the detection of the six pesticides.

\section{Recovery test of six pesticides spiked in tomato}

The MRLs in tomato were $3 \mathrm{mg} / \mathrm{kg}$ for azoxystrobin, $5 \mathrm{mg} / \mathrm{kg}$ for boscalid, $1 \mathrm{mg} / \mathrm{kg}$ for chlorofenapyr, $0.5 \mathrm{mg} / \mathrm{kg}$ for imazalil, $0.01 \mathrm{mg} / \mathrm{kg}$ for isoxathion, and $1 \mathrm{mg} / \mathrm{kg}$ for nitenpyram. The SPR immunosensor showed adequate sensitivity to detect the concentrations around the MRLs in tomato except for isoxathion. Although isoxathion cannot be detected at the concentration around its MRL, the recovery test containing isoxathion was examined to confirm the possibility of simultaneous detection for the six pesticides. Tomato homogenates were spiked with a mixture of the same concentrations of these pesticides. Each of the final pesticide concentrations were $0.5,1$, and $3 \mathrm{mg} / \mathrm{kg}$. As described in Table 1, the SPR immunosensor showed adequate recovery results: $104-116 \%$ for azoxystrobin, $94-101 \%$ for boscalid, $90-112 \%$ for chlorfenapyr, $96-106 \%$ for imazalil, $107-119 \%$ for isoxathion, and $104-109 \%$ for nitenpyram. The relative standard deviation (RSD) values also showed a high repeatability between $0.8-8.5 \%$. The SPR immunosensor constituted could simultaneously and quantitatively detect these pesticides spiked in tomato.

\section{Correlation results between the HPLC and the SPR immunosensor}

Applicability of the SPR immunosensor was further confirmed by comparison with HPLC or LC-MS/MS. As shown in Fig. 5, the results from the SPR immunosensor highly correlated with the results from LCs, except for nitenpyram. The correlation coefficient was $0.91-0.99$ as $R^{2}$ without strong bias except for nitenpyram. The SPR immunosensor for nitenpyram was too low in sensitivity to apply to the incurred samples. However, the results from the three samples, in which nitenpyram resided at comparatively high concentrations, suggested that the SPR immunosensor results would be correlative to the HPLC results. Their correlation results suggested that the SPR immunosensor 

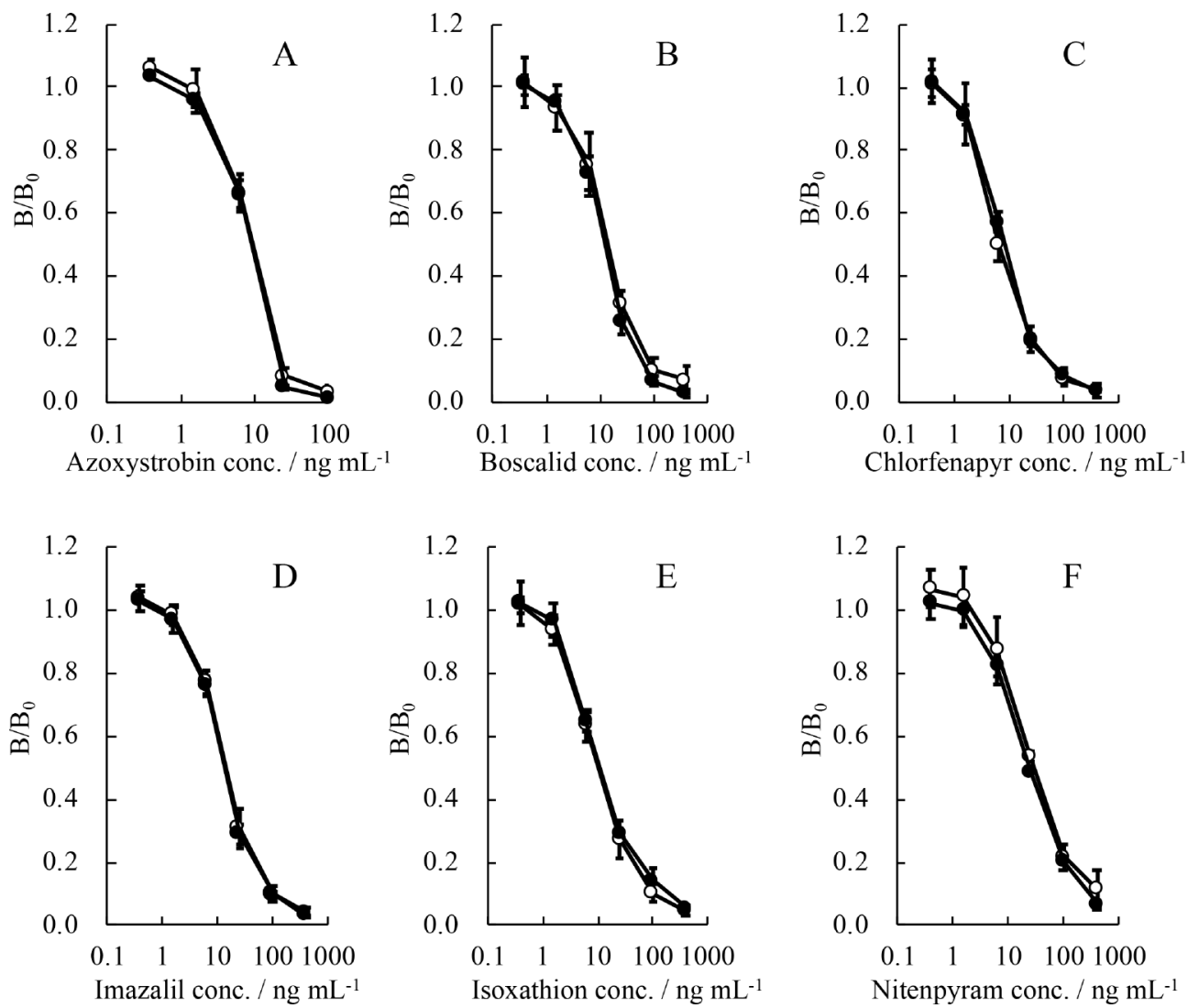

Fig. 4 Inhibition curves of each of the following pesticides by SPR immunosensor: (A) azoxystrobin, (B) boscalid, (C) chlorfenapyr, (D) imazalil, (E) isoxathion, and (F) nitenpyram. Close circle ( shows inhibition curve of each pesticide for single MoAb with its corresponding pesticide. Open circle $(\bigcirc)$ shows inhibition curve of each pesticide for the mixture of six MoAbs with the mixture of six pesticides. Each data point is the mean of triplicate in independent examinations; error bars indicate $\pm \mathrm{SD} . \quad B / B_{0}=\% \Delta R$ on the competitive reaction of the hapten-BSA and the corresponding $\mathrm{MoAb}$ with pesticides $/ \% \Delta R$ on the reaction of the hapten-BSA and the corresponding MoAb without pesticides.

Table 1 Recovery of six pesticides spiked in tomato by SPR immunosensor

\begin{tabular}{|c|c|c|c|c|c|c|}
\hline \multirow{3}{*}{$\begin{array}{l}\text { Pesticide } \\
\text { name }\end{array}$} & \multicolumn{6}{|c|}{ Spiked concentration $/ \mathrm{mg} \mathrm{kg}^{-1}$} \\
\hline & \multicolumn{2}{|c|}{0.5} & \multicolumn{2}{|l|}{1} & \multicolumn{2}{|l|}{3} \\
\hline & Recovery & RSD & Recovery & RSD & Recovery & RSD \\
\hline Azoxystrobin & 104 & 3.3 & 106 & 7.1 & 116 & 6.9 \\
\hline Boscalid & 97 & 6.2 & 94 & 5.7 & 101 & 2.7 \\
\hline Chlorfenapyr & 112 & 6.1 & 90 & 1.0 & 105 & 5.2 \\
\hline Imazalil & 104 & 3.7 & 96 & 2.7 & 106 & 3.5 \\
\hline Isoxathion & 119 & 7.9 & 107 & 3.1 & 110 & 8.5 \\
\hline Nitenpyram & 104 & 6.2 & 107 & 7.1 & 109 & 0.8 \\
\hline
\end{tabular}

would have high applicability for the pesticide residue analyses in the vegetable samples.

\section{Acknowledgements}

The authors express their appreciation to Ms. Miho Nobuchika and Ms. Kyoko Shimomura for their assistance. This study was partially supported by the Aichi Science and Technology Foundation, Japan, and by the Cabinet Office, Government of
Japan, Cross-ministerial Strategic Innovation Promotion Program (SIP), "Technologies for Smart Bio-industry and Agriculture" (funding agency: Bio-oriented Technology Research Advancement Institution, NARO). S. Miyake was employee until March 2018 by HORIBA Ltd., which is the company that provided the MoAbs and sells the SPR imaging system used in this study.

\section{Supporting Information}

Methods of sample preparation for HPLC or LC-MS/MS analysis, HPLC, and LC-MS/MS were described. These materials are available free of charge on the Web at http://www. jsac.or.jp/analsci/.

\section{References}

1. K. J. Brent and D. W. Hollomon, "Fungicide Resistance in Crop Pathogens: How can It be managed?", 2nd ed., 2007, Fungicide Resistance Action Committee, Brussels.

2. T. C. Sparks and R. Nauen, Pestic. Biochem. Physiol., 2015, $121,122$.

3. Y. Akiyama, N. Yoshioka, and M. Tsuji, J. AOAC Int., 2002, 85, 692. 

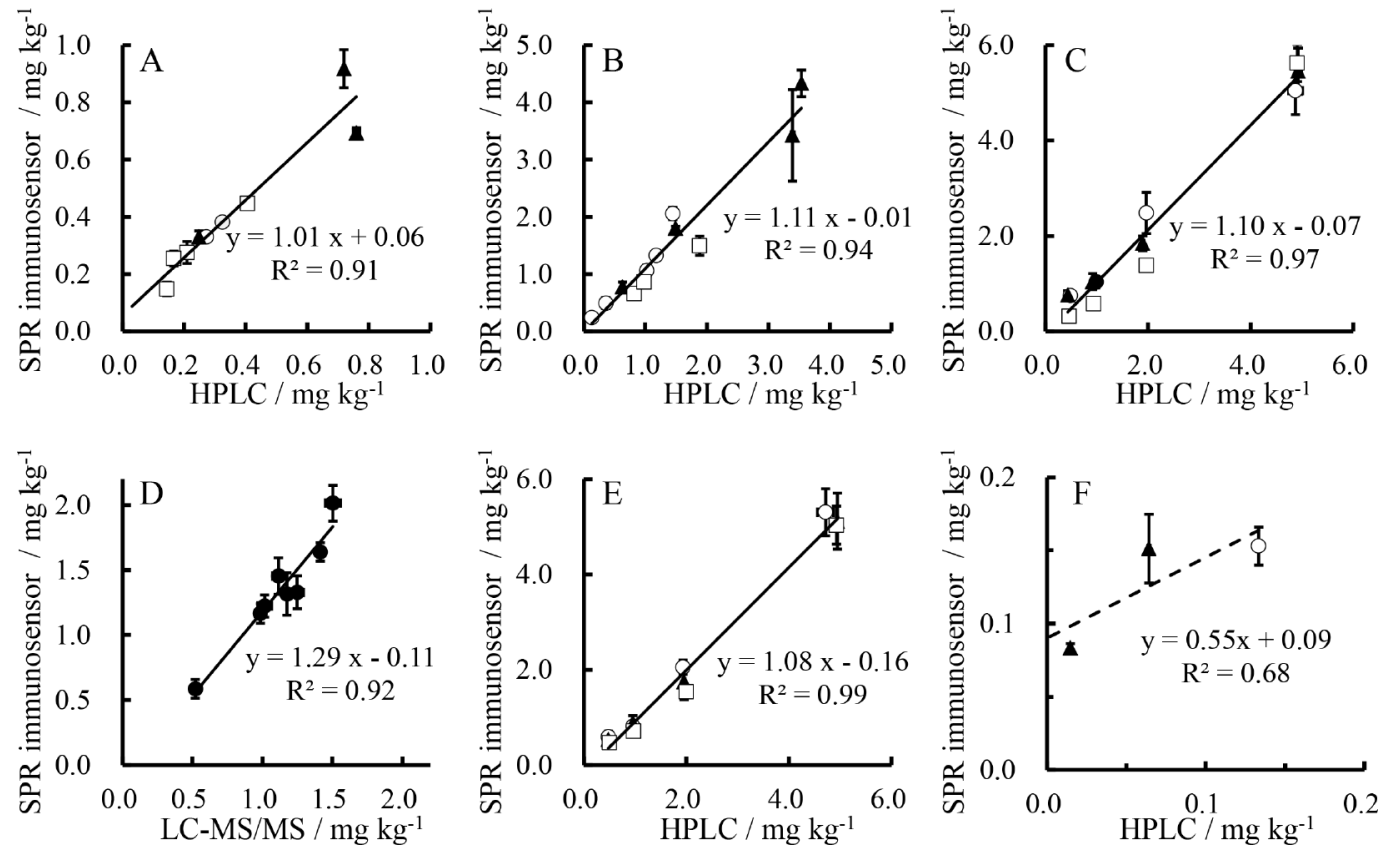

Fig. 5 Correlation of pesticide concentrations determined in eggplant $(\bigcirc)$, tomato $(\square)$, green pepper $(\boldsymbol{A})$, and lemon (O) samples between HPLC and SPR immunosensor for (A) azoxystrobin (cultivated samples), (B) boscalid (cultivated samples), (C) chlorfenapyr (spiked samples), (E) isoxathion (spiked samples), and (F) nitenpyram (cultivated samples), and between LC-MS/MS and SPR immunosensor for (D) imazalil (commercial samples). Each data point is the mean of triplicate in independent examinations; error bars indicate $\pm \mathrm{SD}$.

4. Y. Akiyama, T. Matsuoka, N. Yoshioka, S. Akamatsu, and T. Mitsuhashi, J. Pestic. Sci., 2011, 36, 66.

5. M. Kobayashi, K. Ohtsuka, Y. Tamura, S. Tomizawa, K. Kamijo, K. Iwakoshi, Y. Kageyama, T. Nagayama, and I. Takano, Shokuhin Eiseigaku Zasshi (in Japanese), 2011, 52, 121.

6. E. Ueno, H. Oshima, I. Saito, H. Matsumoto, Y. Yoshimura, and H. Nakazawa, J. AOAC Int., 2004, 87, 1003.

7. M. Okihashi, Y. Kitagawa, K. Akutsu, H. Obana, and Y. Tanaka, J. Pestic. Sci., 2005, 30, 368.

8. S. Takatori, M. Okihashi, Y. Okamoto, Y. Kitagawa, S. Kakimoto, H. Murata, T. Sumimoto, and Y. Tanaka, J. AOAC Int., 2008, 91, 871.

9. A. Stachniuk and E. Fornal, Food Anal. Methods, 2016, 9, 1654.

10. M. Kondo, K. Tsuzuki, H. Hamada, Y. MurakamiYamaguchi, M. Uchigashima, M. Saka, E. Watanabe, S. Iwasa, H. Narita, and S. Miyake, J. Agric. Food Chem., 2012, 60, 904.

11. F. Okazaki, Y. Hirakawa, Y. Yamaguchi-Murakami, A. Harada, E. Watanabe, S. Iwasa, H. Narita, and S. Miyake, Food Hyg. Saf. Sci., 2014, 55, 65.

12. Y. Hirakawa, T. Yamasaki, A. Harada, T. Ohtake, K. Adachi, S. Iwasa, H. Narita, and S. Miyake, J. Agric. Food Chem., 2015, 63, 8075.

13. S. Miyake, Y. Hirakawa, T. Yamasaki, E. Watanabe, A. Harada, K. Adachi, S. Iwasa, and H. Narita, J. Pestic. Sci., 2019, 44, 156.

14. E. Watanabe and S. Miyake, Food Chem., 2013, 136, 695.

15. T. Yamasaki, T. Inoue, Y. Hirakawa, S. Miyake, E. Ueno, and I. Saito, Food Hyg. Saf. Sci. (in Japanese), 2015, 56, 240.
16. S. Miyake, Shokubutsuboeki (in Japanese), 2018, 72, 5.

17. E. Watanabe, T. Yamasaki, Y. Hirakawa, A. Harada, S. Iwasa, and S. Miyake, Anal. Methods, 2018, 10, 3162.

18. E. Watanabe, Y. Hirakawa, T. Yamasaki, S. Iwasa, and S. Miyake, Anal. Lett., 2019, 53, 174.

19. Y. Hirakawa, T. Yamasaki, A. Harada, S. Iwasa, H. Narita, and S. Miyake, Anal. Sci., 2018, 34, 533.

20. S. Ito, M. Hayashi, N. Omoda, M. Watanabe, and S. Watanabe, Japan Patent Application, 1999, 8317199.

21. M. Kawada, K. Morimune, M. Hayashi, A. Fujii, N. Omoda, and S. Watanabe, Japan Patent Application, 1997, 31177397.

22. S. Ito, M. Hayashi, S. Watanabe, A. Fujii, and N. Omoda, Japan Patent Application, 1997, 6568197.

23. J. M. Clough, C. R. F. Godfrey, J. R. Godwin, R. S. I. Joseph, and C. Spinks. Pestic. Outlook, 1996, 7, 16.

24. C. MacBean, "The Pesticide Manual, In: Boscalid", 16th ed., 2012, British Crop Protection Council, Hampshire, 122.

25. C. MacBean, "The Pesticide Manual, In: Chlorfenapyr", 16th ed., 2012, British Crop Protection Council, Hampshire, 176.

26. E. Laville, P. R. Herding, Y. Dagan, M. Rahat, and A. J. Kraght, Proc. Int. Soc. Citriculture, 1977, 1, 269.

27. N. Sampei, K. Tomita, H. Tsuji, T. Yanai, H. Oka, and T. Yamamoto, Ann. Rep. Sankyo Res. Lab., 1970, 22, 221.

28. I. Minamida, K. Iwanaga, T. Tabuchi, I. Aoki, T. Fusaka, H. Ishizuka, and T. Okauchi, J. Pestic. Sci. 1993, 18, 41.

29. A. Akayama and I. Minamida, "Nicotinoid Insecticides and the Nicotinic Acetylcholine Receptor", ed. I. Yamamoto and J. E. Kacida, 1999, Springer, Berlin, 127. 